Nat. Hazards Earth Syst. Sci., 18, 1073-1078, 2018

https://doi.org/10.5194/nhess-18-1073-2018

(C) Author(s) 2018. This work is distributed under

the Creative Commons Attribution 4.0 License.

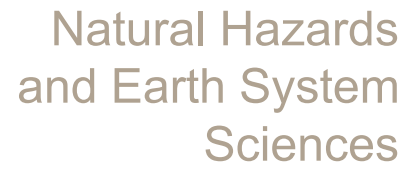

\title{
Brief communication: Loss of life due to Hurricane Harvey
}

\author{
Sebastiaan N. Jonkman ${ }^{1}$, Maartje Godfroy ${ }^{1}$, Antonia Sebastian ${ }^{1,2}$, and Bas Kolen ${ }^{3,4}$ \\ ${ }^{1}$ Department of Hydraulic Engineering, Faculty of Civil Engineering \& Geosciences, Delft University of Technology, \\ Delft, the Netherlands \\ ${ }^{2}$ Department of Civil \& Environmental Engineering, Rice University, Houston, Texas \\ ${ }^{3}$ Department of Values, Technology, and Innovation, Faculty of Technology, Policy, and Management, Delft University of \\ Technology, Delft, the Netherlands \\ ${ }^{4}$ HKV Consultants, Lelystad, the Netherlands
}

Correspondence: Maartje Godfroy (m.godfroij@tudelft.nl) and Sebastiaan N. Jonkman (s.n.jonkman@tudelft.nl)

Received: 7 December 2017 - Discussion started: 3 January 2018

Revised: 18 March 2018 - Accepted: 20 March 2018 - Published: 19 April 2018

\begin{abstract}
An analysis was made of the loss of life caused by Hurricane Harvey. Information was collected for 70 fatalities that occurred due to the event and were recovered within the first 2 weeks after landfall. Most fatalities occurred due to drowning $(81 \%)$, particularly in and around vehicles. Males $(70 \%)$ and people over 50 years old $(56 \%)$ were overrepresented in the dataset. More than half of the fatalities occurred in the greater Houston area $(n=37)$, where heavy rainfall and dam releases caused unprecedented urban flooding. The majority of fatalities were recovered outside the designated 100- and 500-year flood hazard areas.
\end{abstract}

\section{Introduction and background}

Loss of life is one of the most critical consequences of floods. Previous analyses of flood fatalities have focussed on certain regions (Coates, 1999; Zahran et al., 2008; Ashley and Ashley, 2008) and the causes and circumstances of fatalities based on aggregated data for multiple smaller events (Jonkman and Kelman, 2005). Documentation of flood events with significant loss of life is scarce and limited to a few cases, such as the flooding of New Orleans due to Hurricane Katrina (2005) (Jonkman et al., 2009) or more general data for large-scale events such as cyclones in Bangladesh (1991) (Chowdhury et al., 1993). However, detailed analysis of mortality during past flood events is important for the development and improvement of consequence and risk models, and to inform policies and public communication so they can reduce losses during future flood events.
On 25 August 2017, Hurricane Harvey made landfall near Rockport, Texas as a Category 4 storm with maximum sustained winds of approximately $200 \mathrm{~km} \mathrm{~h}^{-1}$. Harvey caused severe damage in coastal Texas due to its extreme winds and storm surge, but will go down in history for record-setting rainfall and flood-related damage in southeast Texas. Rainfall totals during the 6-day period between 25 and 31 August 2017 were amongst the highest ever recorded in US history. Across large portions of southeast Texas, rainfall exceeded $1000 \mathrm{~mm}$. The highest recorded rainfall total was $1539 \mathrm{~mm}$ (60.58 inches) in Nederland, Texas near Port Arthur (Blake and Zelinsky, 2018).

The city of Houston and the surrounding areas experienced unprecedented urban flooding. Many of Houston's creeks and bayous exceeded their channel capacities, reaching water levels never before recorded, and widespread pluvial flooding was reported in communities across the greater Houston area on the morning of 27 August. While the floodwaters in most areas receded within $24-48 \mathrm{~h}$ after the heaviest rainfall, in a smaller number of areas (e.g., downstream of Addicks and Barker reservoirs), water levels remained elevated for a period of days to weeks. It is estimated that more than 80000 homes were affected by flooding of at least $46 \mathrm{~cm}$ (18 inches) (FEMA, 2017). In parts of Houston, the 3-day rainfall during Harvey has been estimated to have exceeded a 9000 -year event (van Oldenborgh et al., 2017).

During the period between 25 and 31 August rising waters necessitated major rescue operations. In total, more than 120000 people were rescued by professional and volunteer rescuers (FEMA, 2017). No large-scale mandatory evacua- 


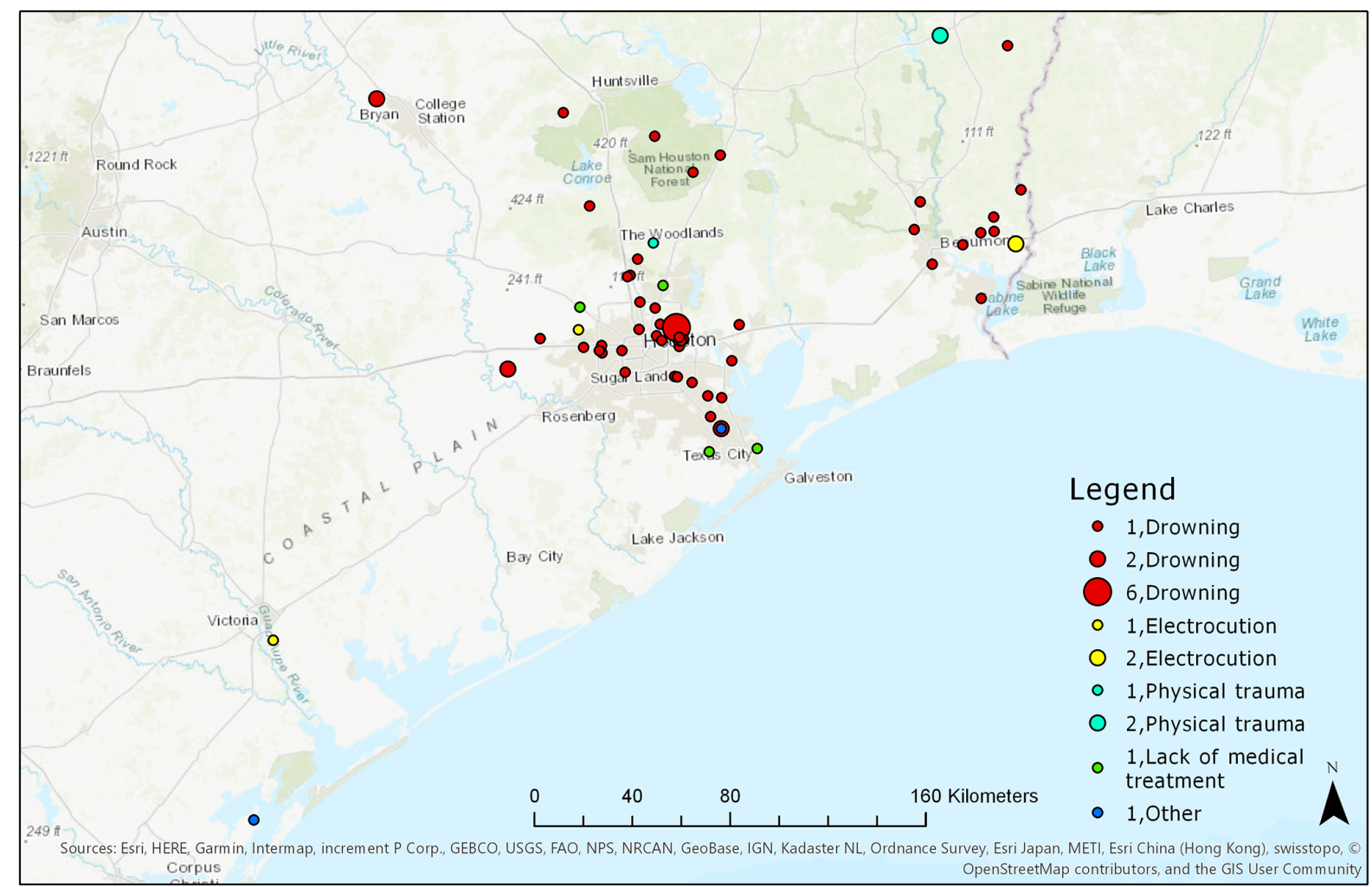

Figure 1. Locations and causes of fatalities due to Hurricane Harvey in Texas as of 8 September 2017.

tion was ordered by the mayor of Houston before or during Harvey, as the risks of evacuating millions of people were considered too high. Instead, people were advised to shelter at home and to prepare themselves. However during the course of the event several local evacuations were ordered for areas with specific risks and circumstances, e.g., Fort Bend County near the Brazos River.

As part of a larger rapid fact-finding effort in the wake of Hurricane Harvey (Sebastian et al., 2017), a dataset of flood fatalities was compiled. The objective of this paper is to analyze the causes and circumstances of the fatalities in southeast Texas due to Hurricane Harvey.

\section{Data and methods}

In order to analyze the Harvey-related fatalities, a database of reported flood fatalities was compiled (Godfroy and Jonkman, 2017). Information about the personal characteristics (age, gender) of the casualties and the location, time of recovery and circumstances of death were included.

The database is limited to fatalities that were recovered within the first 2 weeks after landfall (25 August-8 September 2017). Following the definitions adopted by the National Weather Service (2016) a distinction is made between direct fatalities, i.e., those directly attributed to the hydrometeorological event, and indirect fatalities, i.e., those that occur in the vicinity of a hydrometeorological event, or after it has ended, but are not directly caused by impact or debris from the event.

The dataset was compiled using both official government sources and media reports. In the days after Hurricane Harvey, information about casualties appeared mostly on local news websites. Official reporting on casualties and the level of detail varied greatly between counties. Harris County, where most of the casualties occurred, is the only county at the time of writing that has published an official and public list of casualties (IFS, 2017).

\section{Results}

Based on our analysis, at least 70 deaths can be attributed to Hurricane Harvey. The fatalities occurred across 14 counties with a large spatial scatter throughout southeast Texas. Approximately half of the casualties (37 out of 70 ) were located in Harris County. This is the most densely populated county in the affected area and it was severely affected by flooding. Six fatalities occurred in Orange County around the city of Beaumont and in Galveston County, south of Houston. The recovery locations of the fatalities are shown for the state of Texas (Fig. 1) and for Harris County, which covers a large part of the Houston area (Fig. 2). For Harris County the 100and 500-year floodplains have been added using the FEMA 


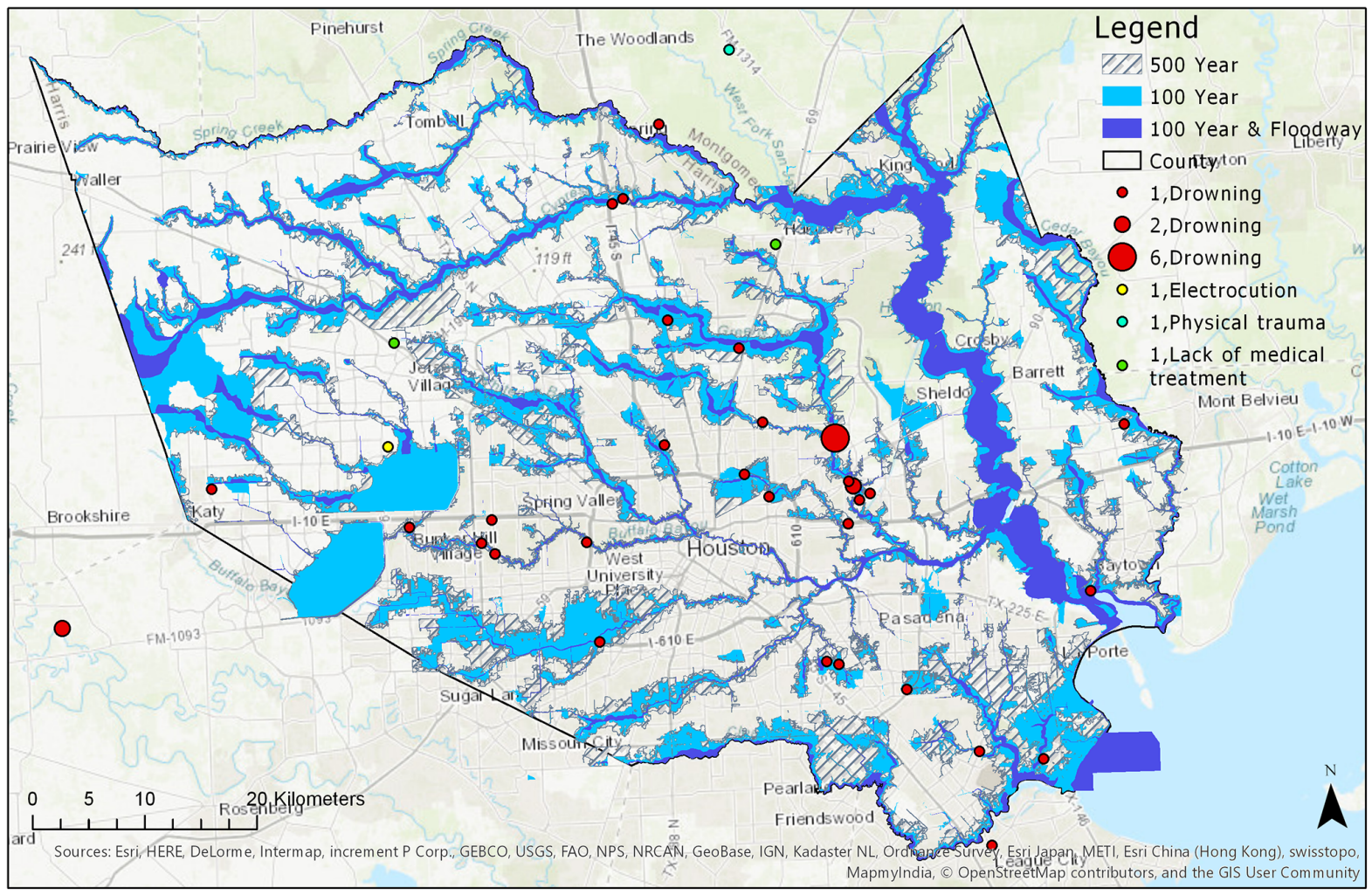

Figure 2. Locations and causes of fatalities due to Hurricane Harvey in the Houston metropolitan area (Harris County) as of 8 September 2017. For the people who died in the hospital (4), the location of the hospital is shown.

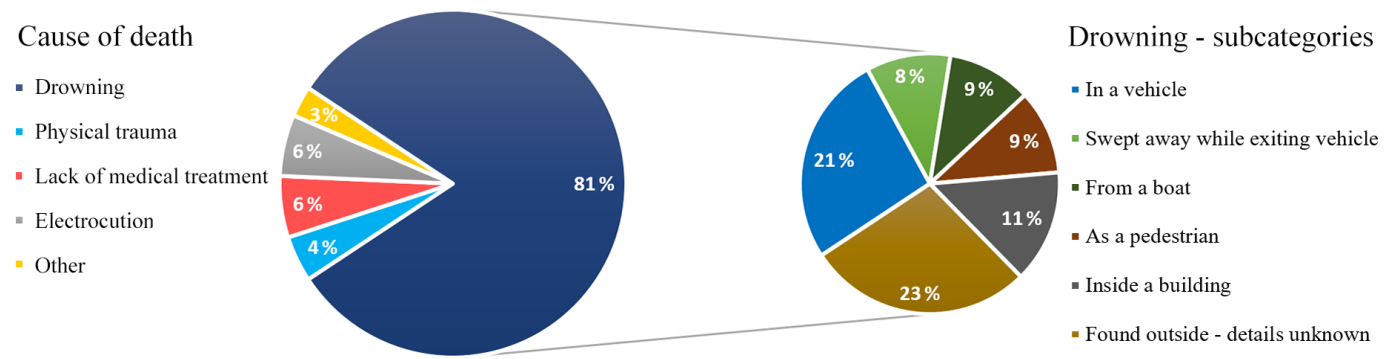

Figure 3. Causes of death for Hurricane Harvey $(n=70)$.

National Flood Hazard Layer available through the Texas Natural Resources Information System (TNRIS) (TNRIS, 2017). Of the 37 casualties in Harris County, 18 were located inside the designated 500-year floodplain, 8 of which were in the 100-year floodplain. Also, at the state level most fatalities ( 37 - so $53 \%$ ) occurred outside the 500-year floodplain. Thirty-three fatalities (47\%) occurred within the 500year floodplain, 14 of which are in the 100-year floodplain. Four casualties occurred in hospitals which are not located in the designated floodplains. The majority of all fatalities $(80 \%)$ occurred within the first 7 days after landfall.

Figure 3 shows an overview of the causes and circumstances of death. Most fatalities were caused by drowning
( 57 out of $70 ; 81 \%$ ), so were directly due to the event. Many of the casualties were discovered after floodwaters had receded and some were even recovered in the second week after the landfall of Harvey.

A significant proportion of the fatalities drowned as a result of driving a vehicle into floodwaters or getting swept away by the current while getting out of a car (confirmed for 21 of 57 drowning fatalities). A tragic example is a case in which six individuals of one family, including four children, drowned when their van was swept off a flooded road by the current and ended up in high water in east Houston. A small number of casualties ( 8 of 57 drowned casualties) were found inside buildings after the floodwater receded. Six peo- 
ple drowned when their boat capsized, while they were trying to rescue residents in need from their flooded houses. It is unknown whether these people wore life jackets. Twentyeight percent of the drowning fatalities (16 out of 57) were recovered in the open and no further information on the exact circumstances was available.

The other fatalities $(19 \%)$ were due to indirect causes. Electrocution and lack of medical treatment each caused four fatalities. The category "lack of medical treatment" includes fatalities that occurred when (very) ill people were not able to gain access to proper treatment in time (i.e., dialysis or treatment of asthma and heart conditions). A smaller number of fatalities occurred due to other causes such as physical traumas (i.e., car accidents, falling trees) $(n=3)$ or infection due to contact with contaminated floodwater $(n=1)$.

Of the fatalities, $70 \%$ were male and $30 \%$ were female. This distribution is in line with findings for previous floods in which it has been suggested that males are more likely to be involved in high-risk activities, such as driving during flooding and high-water rescues (Jonkman and Kelman, 2005).

The age distribution was also analyzed: $9 \%$ of the fatalities were younger than 18 , whereas $56 \%$ of fatalities were older than 50 years and $29 \%$ older than 65 , suggesting an increased vulnerability of people above 50 years old.

\section{Discussion}

The previous analyses are based on data gathered from a combination of official public sources and media sources. When only information from the official source for Harris County was utilized $(N=37)$, findings with respect to the significance of drowning (92\%) and the overrepresentation of males $(73 \%)$ were still obtained.

The present analysis is based on a dataset that includes 70 fatalities due to Harvey. Smith et al. (2017) reported 84 fatalities for the event. A difference could be due to the selection criteria. Local media have reported at least 10 other casualties. These were not included in the present database when the relationship with Hurricane Harvey could not be confirmed by the authorities or when no additional details on the deaths or incident were released.

Of the 37 casualties in Harris County, only $22 \%$ occurred within the designated 100-year floodplain - used as the primary delineation of flood risk in the United States - and $49 \%$ within the 500-year floodplain. This is in line with previous research which finds that in the greater Houston region, the 100-year floodplains have served as a poor predictor of the location of damaging flooding (Highfield et al., 2013; Brody et al., 2018; Blessing et al., 2017). While the flooding from Hurricane Harvey should be expected beyond the 100-year and even 500-year floodplains, our finding also suggests that high-hazard areas outside of the floodplain, such as low water crossings, have not been adequately delineated or communicated to the public. As future work it is recommended to recreate and map the flood conditions during Harvey based on modeling and field observations to better understand the flood conditions at the time and location of the fatalities.

Previous studies have concluded that the majority of fatalities during Atlantic tropical cyclone events occur due to flooding, particularly due to storm surge (Rappaport, 2014). During Harvey, most fatalities were associated with inland flooding in the greater Houston area, primarily driven by Harvey's extreme rainfall. A storm surge of about 2 to $3 \mathrm{~m}$ mainly affected local coastal areas in south Texas and two fatalities were reported in this area.

Findings for Harvey can be compared to other events that affected the same region. During Hurricane Ike (2008) only $11 \%$ of the 74 fatalities were due to drowning (Zane et al., 2011). Others were due to injuries and illnesses, partly also related to the mass evacuation. In terms of rainfalldriven flooding there are more similarities to Tropical Storm Allison (2001). Tropical Storm Allison dropped more than $762 \mathrm{~mm}$ (30 inches) of rainfall over the eastern portion of Harris County in 5-9 June 2001. The event led to 41 fatalities, 23 of which occurred in Texas (Stewart, 2001). Twentyseven deaths were attributed to drowning from freshwater flooding during Tropical Storm Allison.

It is estimated that more than 100000 people were directly affected by floodwaters from Harvey. The overall mortality is thus smaller than $0.1 \%$ which is an order lower than typical mortality values reported for storm surge flooding, which are around $1 \%$, such as for New Orleans (Jonkman et al., 2009). However, the flooding of Houston is expected to be less deadly than those in New Orleans during Katrina for a number of reasons: flood depths and flow velocities in most areas were lower, waters receded more quickly, and people were better warned about flooding beforehand. Still, during Harvey the great majority of fatalities occurred due to drowning, especially in and around vehicles, but relatively few fatalities (11\% of the total) were found in buildings.

The findings also provide a basis for policy recommendations. Following previous studies (Kolen, 2013; Jonkman and Kelman, 2005; Drobot et al., 2007), it is clear that driving on flooded roads is extremely dangerous and several risks are associated with rescue cleanup and recovery (e.g., electrocution, $\mathrm{CO}$ poisoning). Results of this study and findings from previous floods in the Houston area can be used to identify high-risk areas for drowning, such as low-water crossings. During future events, preventive closure of these areas could be considered. Loss of life is influenced by individuals' behavior and the warning and evacuation strategy by the government (Chowdhury et al., 1993; French et al., 1983; Parker et al., 2009). The events during Harvey can also be utilized to evaluate and improve the performance of the evacuation strategy and emergency management for the region, also addressing the need for timely evacuation from specific highrisk areas.

The present study mostly focussed on direct fatalities during and shortly after the event. Analysis and recording of 
longer-term health impacts are recommended. Finally, standardized data collection for future events is recommended to provide a wider data basis and better information for prevention and public communication to avoid future flood fatalities.

Data availability. The database that was used is publicly accessible at the data repository of the Dutch 4TU.federation (Godfroy and Jonkman, 2017).

Competing interests. The authors declare that they have no conflict of interest.

Acknowledgements. Sebastiaan N. Jonkman acknowledges support from the Dutch NWO TTW projects SAFElevee (project number 13861) and All Risk (P15-21). The contributions by Paul Risher and Jason T. Needham (USACE HEC) are gratefully acknowledged. The comments and suggestions by Ilan Kelman and two anonymous reviewers have been very valuable to improve the manuscript.

Edited by: Bruno Merz

Reviewed by: Ilan Kelman and two anonymous referees

\section{References}

Ashley, S. T. and Ashley, W. S.: Flood Fatalities in the United States, J. Appl. Meteorol. Clim., 47, 805-818, https://doi.org/10.1175/2007jamc1611.1, 2008.

Blake, E. S. and Zelinsky, D. A.: National Hurricane Center Tropical Cyclone Report, Miami, FL, available at: https:// www.nhc.noaa.gov/data/tcr/AL092017_Harvey.pdf, last access: 6 March 2018.

Blessing, R., Sebastian, A., and Brody, S. D.: Flood Risk Delineation in the United States: How Much Loss Are We Capturing?, Nat. Hazards Rev., 18, 4017002, https://doi.org/10.1061/(asce)nh.1527-6996.0000242, 2017.

Brody, S. D., Sebastian, A., Blessing, R., and Bedient, P. B.: Case study results from southeast Houston, Texas: identifying the impacts of residential location on flood risk and loss, J. Flood Risk Manage., 11, 110-120, https://doi.org/10.1111/jfr3.12184, 2018.

Chowdhury, A. M. R., Bhuyia, A. U., Choudhury, A. Y., and Sen, R.: The Bangladesh Cyclone of 1991: Why So Many People Died, Disasters, 17, 291-304, https://doi.org/10.1111/j.14677717.1993.tb00503.x, 1993.

Coates, L.: Flood Fatalities in Australia, 1788-1996, Austral. Geogr., 30, 391-408, https://doi.org/10.1080/00049189993657, 1999.

Drobot, S., Benight, C., and Gruntfest, E.: Risk factors for driving into flooded roads, Environ. Hazards, 7, 227-234, https://doi.org/10.1016/j.envhaz.2007.07.003, 2007.

FEMA: Historic Disaster Response to Hurricane Harvey in Texas, https://www.fema.gov/news-release/2017/09/22/ historic-disaster-response-hurricane-harvey-texas, last access: 1 December 2017.

French, J., Ing, R., Von Allmen, S., and Wood, R.: Mortality From Flash Floods: A Review of National Weather Service Reports, 1969-81, Publ. Health Rep., 98, 584-588, 1983.

Godfroy, M. and Jonkman, S. N.: Fatalities due to hurricane Harvey (2017), 4TU Federation, https://doi.org/10.4121/uuid:95690fdd-b13f-4bf9-a28dc9b924696a96, 2017.

Highfield, W. E, Norman, S. A., and Brody, S. D.: Examining the 100-Year Floodplain as a Metric of Risk, Loss, and Household Adjustment, Risk. Anal., 33, 186-191, https://doi.org/10.1111/j.1539-6924.2012.01840.x, 2013.

IFS: Confirmed Hurricane Harvey-Related Fatalities, https://ifs.harriscountytx.gov/Documents/ HarrisCountyHarvey-RelatedDeaths.pdf (last access: 1 March 2018), 2017.

Jonkman, S. N. and Kelman, I.: An Analysis of the Causes and Circumstances of Flood Disaster Deaths, Disasters, 29, 75-97, https://doi.org/10.1111/j.0361-3666.2005.00275.x, 2005.

Jonkman, S. N., Maaskant, B., Boyd, E., and Levitan, M. L.: Loss of Life Caused by the Flooding of New Orleans After Hurricane Katrina: Analysis of the Relationship Between Flood Characteristics and Mortality, Risk Analysis, 29, 676-698, https://doi.org/10.1111/j.1539-6924.2008.01190.x, 2009.

Kolen, B.: Certainty of uncertainty in evacuation for threat driven responses; Principles of adaptive evacuation management for flood risk planning in the Netherlands, $\mathrm{PhD}$ Thesis, University of Nijmegen, Nijmegen, 2013.

National Weather Service: Storm data preparation, National Weather Service instruction 10-1605,http://www.nws. noaa.gov/directives/sym/pd01016005curr.pdf (last access: 23 March 2016), 2017.

Parker, D. J., Priest, S. J., and Tapsell, S. M.: Understanding and enhancing the public's behavioural response to flood warning information, Meteorol. Appl., 16, 103-114, 2009.

Rappaport, E. N.: Fatalities in the United States from Atlantic Tropical Cyclones: New Data and Interpretation, B. Am. Meteorol. Soc., 95, 341-346, https://doi.org/10.1175/BAMS-D-1200074.1, 2014.

Sebastian, A., Lendering, K. T., Kothuis, B. L. M., Brand, A. D., and Jonkman, S. N.: Hurricane Harvey Report: A fact-finding effort in the direct aftermath of Hurricane Harvey in the Greater Houston Region, Delft University Publishers, Delft, 2017.

Smith, A., Lott, N., Houston, T., Shein, K., Crouch, J., and Enloe, J.: U.S. Billion-Dollar Weather \& Climate Disasters 1980-2017, NOAA, https://www.ncdc.noaa.gov/billions/events.pdf, last access: 1 December 2017.

Stewart, S. R.: Tropical Cyclone Report: Tropical Storm Allison 517 June 2001, National Hurricane Center, http://www.nhc.noaa. gov/data/tcr/AL012001_Allison.pdf (last access: 1 March 2018), 2001.

TNRIS: Texas Natural Resources Information System, https://tnris. org/data-download/\#!/statewide (last access: 1 March 2018), 2017.

van Oldenborgh, G. J., van der Wiel, K., Sebastian, A., Singh, R., Arrighi, J., Otto, F., Haustein, K., Li, S., Vecchi, G., and Cullen, H.: Attribution of the Extreme Rainfall from Hurricane, 
Environm. Res. Lett., 12, 124009, https://doi.org/10.1088/17489326/aa9ef2, 2017.

Zahran, S., Brody, S. D., Peacock, W. G., Vedlitz, A., and Grover, H.: Social vulnerability and the natural and built environment: a model of flood casualties in Texas, Disasters, 32, 537-560, https://doi.org/10.1111/j.1467-7717.2008.01054.x, 2008.
Zane, D. F., Bayleyegn, T. M., Hellsten, J., Beal, R., Beasley, C., Haywood, T., Wiltz-Beckham, D., and Wolkin, A. F.: Tracking Deaths Related to Hurricane Ike, Texas, 2008, Disast. Med. Publ. Health Prepared., 5, 23-28, https://doi.org/10.1001/dmp.2011.8, 2011. 